\title{
KÉO DÀI THỜI GIAN BẢO QUẢN TRÁI BƠ (Persea americana) BẰnG BAO MÀNG PHỨC HỢP CHITOSAN-SODIUM TRIPOLYPHOSPHATE
}

\author{
NGUYỄN ĐỨC VƯợNG, LÊ THỊ HỒNG TRANG, LÊ THỊ NHỊ, ĐINH THỊ HỒNG NHUNG, TRÂN \\ THI DIỄM PHU'OONG, NGUYẼ̃N HUỲNH ĐİNH THUÂN \\ Viện Công nhệ Sinh học và Thưc phẩm, Truờng Đại học Công nghiệp Thành phố Hồ Chí Minh \\ nguyenducvuong@iuh.edu.vn
}

Tóm tắt. Nghiên cứu này đánh giá ảnh hưởng của việc bao màng chitosan $(\mathrm{CH})$ ở các nồng độ khác nhau, kêt hợp $0,01 \%$ sodium tripolyphosphate (TPP) đến chất lượng trái bơ booth. Trái bơ booth được nhúng trong nước ấm $\left(\sim 55^{\circ} \mathrm{C}\right)$ trong 30 giây, rồi được nhúng trong dung dịch axit axetic $1 \%$ (mẫu đối chứng), $\mathrm{CH}$ $2,2,5$, và $3 \%$ kết hợp TPP $0,01 \%$ trong 1 phút. Sau khi được để khô tự nhiên, các mẫu được nhúng lần 2 trong 10 giây. Mẫu được để khô tự nhiên, và được bảo quản ở $10 \pm 2^{\circ} \mathrm{C}$. Kết quả cho thấy, tỷ lệ $\mathrm{CO}_{2} \sinh$ ra của mẫu đối chứng đạt cực đại ở ngày 11 , trong khi của các mẫu bơ được bao màng bởi $2,2,5,3 \%$ chitosan đạt tương ứng ở các ngày 17,21 , và 19 . Kết quả tương tự được quan sát thấy ở tỷ lệ ethylen sinh ra ở các ngày bảo quản tương ứng. Tại đỉnh hô hấp, tỷ lệ hao hụt khối lượng của mẫu đối chứng khoảng $20 \%$; cao hơn 3-5 lần so với tỷ lệ này ở các mẫu bơ được bao màng bởi dung dịch $\mathrm{CH} 2,2,5,3 \%$ (tương ứng khoảng $6,6,3,8$, và $4 \%$ ). Đồng thời, hao hụt hàm lượng vitamin $\mathrm{C}$ thấp nhất ghi nhận được trong mẫu bơ bao màng bởi $\mathrm{CH} 2,5 \%$. Dung dịch $\mathrm{CH} 2,5 \%$ và TPP $0,01 \%$ thể hiện khả năng phù hợp bảo quản trái bơ.

Từ khóa. Bao màng, bảo quản, chitosan, trái bơ, tripolyphosphate.

\section{SHELF-LIFE EXTENSION OF AVOCADO FRUIT (PERSEA AMERICANA) WITH CHITOSAN-SODIUM TRIPOLYPHOSPHATE COMPLEX BASED COATING}

\begin{abstract}
The aim of this study was to evaluate the effect of chitosan $(\mathrm{CH})$ combined $0.01 \%$ sodium tripolyphosphate based coating at different concentrations on booth avocado quality. Avocado fruits were washed with warm water $\left(\sim 55^{\circ} \mathrm{C}\right)$ for 30 senconds, then dipped in acetic acid $1 \%$ (control sample), $\mathrm{CH}$ $2.0,2.5,3.0 \%$ combined TPP $0.01 \%$ solutions for 60 seconds. The fruits were dried naturally, and dipped $2^{\text {nd }}$ time for 10 seconds. After natural dry, avocado fruit were stored at $10 \pm 2{ }^{\circ} \mathrm{C}$. The ethylene and $\mathrm{CO}_{2}$ generation percentage, weight loss was determined every day during the storage period; total sugar and vitamin $\mathrm{C}$ contents were determined at the beginning and end points. The results illustrated that, $\mathrm{CH}$ and TPP based coating extended the possible storage period of avocado fruit. The $\mathrm{CO}_{2}$ generation reached maximum at day- 11 of control sample, while this peak of avocado coated with $\mathrm{CH} 2,2.5$ and $3 \%$ and TPP $0.01 \%$ got at day of 17,21 , and 19 , respectively. The similar trend and rersult were observed on ethylene generation of these samples, respectively. Furthermore, the control sample showed almost $20 \%$ in weight loss at the climacteric peak. It was 3-5 fold when compared to that of avocado fruit coated with $\mathrm{CH} \mathrm{2,2.5}$ and $3 \%$ and TPP $0.01 \%$ (about $6.6,3.8$ and $4 \%$, respectively). In addition, the lowest vitamin $\mathrm{C}$ content loss was observed in $\mathrm{CH} 2.5 \%$ based coated avocado fruit. The chitosan $2.5 \%$ and TPP $0.01 \%$ showed the higher potential for prolonging the storage-time of avocado compared to the others.
\end{abstract}

Keywords. Avocado, coating, chitosan, postharvest, tripolyphosphate.

\section{GIỚI THIỆ}

Bơ (Persea americana) được trồng ở các vùng có khí hậu nhiệt đới và ôn đới. Ở Việt Nam, bơ được trồng chủ yếu ở các tỉnh Dak lak, Lâm Đồng, Gia Lai, Đồng Nai, Bà Rịa, v.v. Bơ booth, một loại bơ có giá trị cao và phổ biến ở Việt nam, có cơm dày, màu vàng, cơm có độ dẻo, độ chắc cao và vị thơm đặc trưng. Bơ chứa nhiều thành phần dinh dưỡng, axit béo - đặc biệt là axit béo chưa bão hòa, vitamins và khoáng. Việc chuyển hóa và vai trò của các chất này trong cơ thể đã được nghiên cứu và công bố. Bơ, bên cạnh việc cung cấp năng lượng, có khả năng hỗ trợ sức khỏe người tiêu dùng như giúp ổn định cholesterol, kiểm soát cân nặng, tiểu đường và phòng chống ung thư, v.v. [1]. Các nghiên cứu chứng minh rằng các công dụng này dược chủ yếu hỗ trợ bởi sự có mặt của các axit béo, xơ tinh, D-mannoheptulose và perseitol, kali, magie, vitamins $\mathrm{C}, \mathrm{E}, \mathrm{K}$ và $\mathrm{B}$, carotenoids, phenolics, phytosterols hoặc terpenoids trong trái bơ [2]. 
Bơ là trái cây hô hấp đột biến, có thời gian bảo quản ngắn [3]. Ở điều kiện thường, bơ sẽ chín sau 4-7 ngày từ khi thu hoạch, tùy vào độ trưởng thành của trái bơ. Có 2 nguyên nhân chính gây nên việc này là quá trình hô hấp của trái diễn ra mạnh và nấm Colletotrichum gloeosporioides. Nấm C. gloeosporioides gây hư hỏng và làm mềm trái bơ. Quá trình chín cùng với sự chuyển hóa thành phần trong trái bơ liên quan đến nhiệt độ và ethylene trong quá trình bảo quản $[4,5]$. Bảo quản ở nhiệt độ thấp làm chậm quá trình hô hấp của trái trong quá trình chín $[5,6]$. Khi ethylene sản sinh đạt giá trị lớn nhất, cũng là lúc tốc độ hô hấp, tương ứng với lượng $\mathrm{CO}_{2}$ đạt cực đại. [7]

Nghiên cứu về việc bảo quản trái bơ vẫn còn hạn chế. Các nghiên cứu, đã công bố, tập trung vào hai kỹ thuật chính là sử dụng chất ức chế hoạt động của ethylene trong quá trình chín của trái bơ sau khi thu hoạch 1-Methylcyclopropene $(1-\mathrm{MCP})[8,9]$, và bao màng bằng vật liệu thiên nhiên ăn được như sáp [10], sáp cọ tổng hợp candelilla wax [11,12], pectin [11], chitosan và carboxymethyl cellulose [13]. Bên cạnh đó, có một số nghiên cứu kết hợp vật liệu bao màng thiên nhiên với các hợp chất thiên nhiên có hoạt tính sinh học như candelilla wax và pectin với dịch nha đam và polyphenol [11], chitosan và carboxymethyl cellulose với dịch chiết lá chùm ngây [13]. Kết quả cho thấy, 1-MCP thể hiện hiệu quả nhất định trong việc làm chậm quá trình chín, kéo dài thời gian và tăng chất lượng của bơ sau bảo quản $[9,14]$. Tuy nhiên, $1-\mathrm{MCP}$ không thật sự hiệu quả trong việc bảo quản những trái cây có nguy cơ bị hư hỏng do nấm bệnh, bởi vì 1-MCP không có tác dụng diệt nấm bệnh như Botrytis cinerea trên trái dâu tây [15], hoặc C. gloeosporioides trên trái bơ [14]. Jeong J. và cộng sự (2003) [10] nghiên cứu kết hợp giữa $1-\mathrm{MCP}$ và sáp trong bảo quản trái bơ. Sự kết hợp này giúp làm chậm quá trình chín, giữ màu xanh của vỏ và cấu trúc của trái bơ. Xử lý với sáp và không kết hợp $1-\mathrm{MCP}$ giúp trái bơ giảm hao hụt khối lượng và làm chậm quá trình mềm hóa, nhưng không làm chậm quá trình sản sinh ethylene cũng như quá trình chín.

Nghiên cứu sử dụng kỹ thuật bao màng trái bơ bằng methyl cellulose và glycerol, và bảo quản ở $20^{\circ} \mathrm{C}$ của Maftoonazad và Ramaswamy (2004) cho thấy, thời gian bảo quản của mâ̂u bao màng là 10 ngày và tỷ lệ hao hụt khối lượng là $4 \%$ so với mẫu đối chứng tương ứng là 6 ngày và $8 \%$ [16]. Tuy nhiên, nghiên cứu này chỉ dừng lại ở so sánh ảnh hưởng của bao màng, chưa xác định sự biến đổi dinh dưỡng của trái bơ [17]. Sáp candelilla cũng được nghiên cứu để bảo quản trái bơ, kết quả chỉ ra rằng khi kết hợp sáp với polyphenol có thể tăng thời gian bảo quản bơ Hass lên 21 ngày trong điều kiện lạnh (so với mẫu đối chứng là 8 ngày), đồng thời hạn chế được sự hao hụt khối lượng. Saul Saucedo-Pompa và cộng sự (2009) công bố rằng, kêt hợp sáp và axit ellagic sử dụng kỹ thuật bao màng, giúp kéo dài thời gian bảo quản trái bo [12]. Việc sử dụng các polymer tự nhiên trong bảo quản trái bơ khi kết hợp với các hợp chất tự nhiên có hoạt tính sinh học thể hiện nhiều hứa hẹn trong việc bảo quản trái bơ [11]. Aguirre-Joya và cộng sự (2017) khi nghiên cứu kết hợp sáp candelilla, pectin với dịch lô hội và polyphenol bảo quản trái bơ, kết luận màng hoạt tính sinh học giúp giảm hao hụt khối lượng $(58 \%)$ và cấu trúc (9 lần), và giữ được màu sáng $(50 \%)$, đồng thời ức chế sự hóa nâu của thị quả bơ (100\%) so với mẫu đối chứng. Ngoài ra, nghiên cứu của Tesfay và Magwaza (2009) kết luận rằng khi kết hợp dịch chiết lá chùm ngây với chitosan và carboxymethyl cellulose giúp giảm hao hụt khối lượng, làm chậm quá trình chín, cải thiện chất lượng trái bơ sau bảo quản so với mẫu đối chứng [13].

Chitosan $(\mathrm{CH})$ là một polymer tự nhiên, có khả năng phân hủy sinh học cao và an toàn cho người. Với tính chất kháng vi sinh vật tốt, $\mathrm{CH}$ được coi là polymer hấp dẫn trong nghiên cứu và ứng dụng bảo quản trái cây. Thêm vào đó, với đặc tính tạo màng ăn được, màng $\mathrm{CH}$ hoạt động như một hàng rào giúp ngăn cản sự bay hơi nước và sự trao đổi khí (Dhall 2013). Trong số các vật liệu bao màng ăn được, $\mathrm{CH}$ được coi là một vật liệu có thể triển khai áp dụng trong thực phẩm ở quy mô công nghiệp, thể hiện qua các công bố về nghiên cứu ứng đụng $\mathrm{CH}$ trong bảo quản trái cây. Màng $\mathrm{CH}$ giảm hao hụt khối lượng và kéo dài thời gian bảo quản trái vải (Dong và cộng sự, 2004); làm chậm quá trình chín của trái đào [18]. Salvador và cộng sự (1999) [19] quan sát được thời gian bảo quản của trái bơ kéo dài tới 24 ngày ở 3$10^{\circ} \mathrm{C}$ khi bao màng chitosan. Trong nghiên cứu gần đây của Tesfay và Magwaza (2017) chứng minh màng bao $\mathrm{CH}$ kết hợp dịch chiết lá chùm ngây cải thiện chất lượng và thời gian bảo quản trái bơ so với mẫu đối chứng.

Sodium Tripolyphosphate (TPP) là tác nhân tạo liên kết liên kết trong dung dịch $\mathrm{CH}$, và được sử dụng để tạp gel $\mathrm{CH}$. Sodium TPP có thể nâng cao tính bền cơ học của gel được tạo thành do nó có mật độ điện tích âm lớn để tương tác với các nhóm tích điện dương, nhóm amino, của phân tử $\mathrm{CH}$ [20]. 
Việc bao màng $\mathrm{CH}$ thể hiện tiềm năng trong ứng dụng bảo quản trái bơ. Nghiên cứu này khảo sát ảnh hưởng của màng phức hợp chitosan - sodium tripolyphosphate trong bảo quản trái bơ booth ở $10 \pm 22^{\circ} \mathrm{C}$.

\section{VÂT LIÊU VÀ PHƯƠNG PHÁP NGHIÊN CÚU}

\subsection{Vật liệu nghiên cứu}

Trái bơ booth được thu hoạch từ rẫy bơ của ông Trịnh Xuân Mười, Xã Eakao, Buôn Ma Thuột, Đăk Lăk. Bơ sau khi tới phòng thí nghiệm, được lựa chọn theo các tiêu chí: kích thước tương đồng, vỏ màu xanh đậm và láng, không bị bệnh, không bị tổn thương vật lý.

Chitosan được cung cấp bởi công ty cổ phần đầu tư thương mại dịch vụ Tin Cậy, địa chỉ số 4, đường số 3 , khu dân cư Vạn Phúc, Phường Hiệp Bình Phước, Quận Thủ Đức, Thành phố Hồ Chí Minh. Chitosan dạng bột (TCVN 5251:2015), độ deacetyl hóa 99,24\% (ISN 1810-03030), độ hòa tan 99,86\% (ISN 181003030).

Các hóa chất khác là các hóa chất tiêu chuẩn phân tích.

\subsection{Phương pháp nghiên cứu}

\subsubsection{Chuẩn bị dịch chitosan}

Dung dịch chitosan ở các nồng độ $2 ; 2,5$ và $3 \%(\mathrm{w} / \mathrm{v})$ : Chitosan được hòa tan từ từ trong dung dịch axit axetic $1 \%(\mathrm{v} / \mathrm{v})$. Sau đó, $0.01 \%$ TPP được bổ sung để tăng tính ổn định của màng. Hỗn hợp được khuấy nhẹ trong 5 phút, và để yên trong 4 giờ để tạo sự đồng nhất.

\subsubsection{Quy trình xử lý mẫu trước bảo quản}

Mỗi thí nghiệm, 6 trái bơ booth được rửa qua nước ấm $\left(\sim 55^{\circ} \mathrm{C}\right)$ trong 30 giây, rồi được nhúng trong các dung dịch axit axetic $1 \%$, chitosan $2 ; 2,5$ và $3 \%$ trong 1 phút. Sau đó, các mẫu được để khô tự nhiên ở nhiệt độ phòng, và tiếp tục nhúng lần 2 trong 10 giây nhằm vá các vị trí màng bao chưa tốt. Sau khi các mẫu khô tự nhiên, được bảo quản ở tủ mát ở $10 \pm 2^{\circ} \mathrm{C}$.

\subsubsection{Phương pháp xác định và phân tích.}

\section{Xác định độ hao hụt khối lự̛ng}

Độ hao hụt khối lượng của trái bơ được tính theo tỷ lệ phần trăm giữa sự suy giảm khối lượng của mẫu bơ ở thời điểm phân tích so với khối lượng ở thời điểm ban đầu của quá trình bảo quản.

\section{Xác định cường độ hô hấp}

Cường độ hô hẩp của quả là số $\mu \mathrm{L}$ khí $\left(\mathrm{CO}_{2}\right)$ tạo ra do trái hô hấp trong một đơn vị thời gian trên một đơn vị khối lượng của trái bơ [9]. Sử dụng thiết bị đo nồng độ khí $\mathrm{CO}_{2}$ (Model $907 \mathrm{O}_{2} / \mathrm{CO}_{2}$ Analyzer), Nhật Bản sản xuất. Kết quả được tính theo công thức (2).

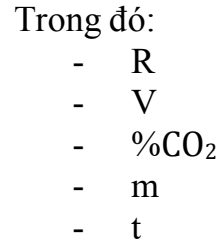

$$
\mathrm{R}=\frac{V * \% C O 2 * 10}{m * t}
$$

\section{Xác định hàm lự̆ng ethylen}

: cường độ hô hấp của quả, $\mu \mathrm{L} \mathrm{CO} 2 \cdot \mathrm{kg}^{-1} \cdot \mathrm{h}^{-1}$

: thể tích tự do của hộp, $\mathrm{L}$

: nồng độ của $\mathrm{CO}_{2}$ đo được trên máy, $\%$

: khối lượng trái đem đo, $\mathrm{kg}$

: thời gian từ lúc đậy mẫu đến lúc đo, $h$.

Hàm lượng ethylene được xác định trên máy đo ethylene ICA 56, Nhật Bản sản xuất. Kết quả được tính theo công thức (3) [9].

$$
\mathrm{E}=\frac{e * V}{m * t}
$$

Trong đó:

- $\quad$ E : tốc độ sản sinh ethylene, $\mu \mathrm{L} \mathrm{C}_{2} \mathrm{H}_{4} \cdot \mathrm{kg}^{-1} \cdot \mathrm{h}^{-1}$

- $\quad \mathrm{V}$ : thể tích tự do của hộp, L

- $\quad \mathrm{e} \quad$ : nồng độ của $\mathrm{C}_{2} \mathrm{H}_{4}$ đo được trên máy, ppm

- $\mathrm{m}$ : khối lượng công thức đem đo, $\mathrm{kg}$

- $\quad \mathrm{t} \quad$ : thời gian từ lúc đậy mẫu đến lúc đo, $\mathrm{h}$ 


\section{Xác định hàm lựng vitamin C}

Hàm lượng vitamin $\mathrm{C}$ trong trái bơ được xác định theo phương pháp chuẩn độ iot theo $\mathrm{TCVN}$ 11168:2015. Mỗi ml dung dịch iot 0,01 $\mathrm{N}$ tương ứn với 0,8806 mg axit ascorbic [21].

Xủ lý kết quả

Kết quả được xử lý bằng phần mềm mã nguồn mở $\mathrm{R} 3.6 .0$ và $\mathrm{R}$-studio. Phân tích phương sai ANOVA kết hợp kiểm định hậu nghiệm TukeyHSD với mức ý nghĩa $p<0,05$. Kết quả được biểu diễn ở dạng trung bình kèm độ lệch chuẩn của các lần lặp.

\section{KẾT QUẢ VÀ BÀN LUẤN}

\subsection{Cường độ hô hấp của trái bo trong quá trình bảo quản}

Kết quả, được biểu diễn trong Hình 1, cho thấy cường độ hô hấp của các mẫu đều giảm ở thời gian đầu của quá trình bảo quản. Nguyên nhân có thể được giải thích bởi sự thay đổi nhiệt độ môi trường xung quanh trái: từ nhiệt độ môi trường xuống nhiệt độ bảo quản $\left(10 \pm 2^{\circ} \mathrm{C}\right)$. Điều này phù hợp với các loại trái cây thuộc loại hô hấp đột biến. Sau đó, hàm hàm lượng $\mathrm{CO}_{2}$ sinh ra tăng nhanh ở cả 4 mẫu. Mẫu đối chứng có tỷ lệ tăng cường độ hô hấp lớn nhất, và đạt đỉnh hô hấp ở ngày 11. Ở tại thời điểm đó, cường độ hô hấp của các mẫu được bao màng với vật liệu khác nhau có độ hô hấp ở mức thấp, dao động xung quanh giá trị ban đầu (Hình 1).

Đồng thời, trong khoảng 10 ngày đầu bảo quản, cường độ hô hấp của 3 mẫu bao màng với nông độ $\mathrm{CH}$ khác nhau không khác biệt có ý nghĩa thống kê. Tiếp theo, cường độ hô hấp của các mẫu bao màng bởi dung dịch $2,2,5$, và $3 \%$ chitosan kết hợp $0,01 \%$ TPP tăng dần và đạt đỉnh hô hấp ở các ngày 17,21 , và 19, theo thứ tự. Có thể giải thích việc bao màng chitosan giúp kéo dài thời gian đạt đỉnh hô hấp của trái bơ khoảng 2 lần là do khi bao màng với $\mathrm{CH}$, phân tử $\mathrm{CH}$ có thể cạnh tranh tốt hơn các phân tử ethylene để gắn kết vào các thụ thể trên mô quả, nhờ vậy mà ức chế tốt hơn tác động của ethylene, dẫn đến hạn chế cường độ hô hấp và kéo dài thời hạn bảo quản quả sau thu hoạch tốt hơn. Ngoài ra, việc bao màng $\mathrm{CH}$ giúp điều chỉnh khí xung quanh trái, cũng có công dụng tương tự như kỹ thuật thay đồi thành phần không khí trong bao gói, và do đó, giúp kìm hãm quá trình hô hấp và kéo dài thời gian bảo quản trái bơ [22]. Cũng theo Zhu và cộng sự (2008), việc bao màng $\mathrm{CH}$ không gây ảnh hưởng đến hô hấp kỵ khí, và do đó không ảnh hưởng đến chất lương của trái cây, có thể được giải thích với màng $\mathrm{CH}$ cho $\mathrm{O}_{2}$ đi qua chọn lọc hơn $\mathrm{CO}_{2}[23]$.

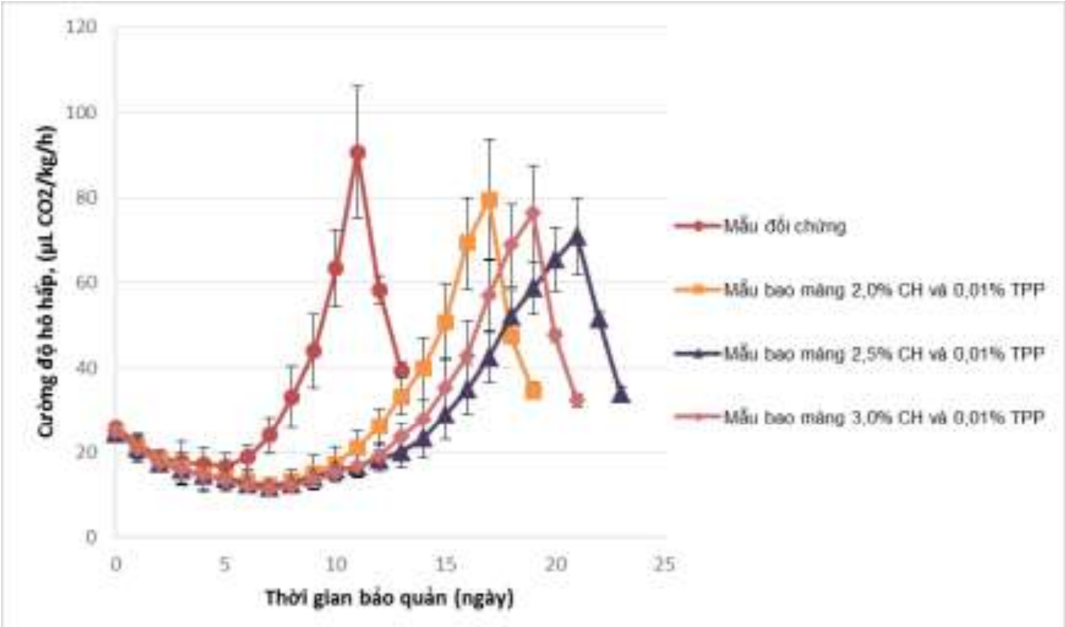

Hình 1. Cường độ hô hấp của trái bơ theo thời gian bảo quản

\subsection{Hàm lượng của ethylen sinh ra trong quá trình bảo quản}

Kết quả thực nghiệm thu được (Hình 2) cho thấy, nồng độ dung dịch $\mathrm{CH}$ ảnh hưởng lớn đến cường độ sản sinh ethylene của trái bơ trong quá trình bảo quản. Sự biến thiên cường độ sản sinh ethylene tương đồng với cường độ sản sinh $\mathrm{CO}_{2}$ theo thời gian bảo quản. Thời điểm cường độ sản sinh ethylene của các mẫu bơ đạt cực đại trùng với thời điểm của các đỉnh hô hâp của các mẫu tương ứng. Cường độ sản sinh ethylene của tất cả các mẫu có xu hướng tăng chậm trong những ngày đầu bảo quản, sau đó đạt giá trị cực đại tại các thời điểm khác nhau rồi giảm đi một cách nhanh chóng sau khi đạt đỉnh hô hấp đột biến. Kết 
quả này phù hợp vì quá trình chín, tốc độ sản sinh $\mathrm{CO}_{2}$ được làm chậm lại khi mẫu được bao màng, lượng ethylene nội sinh cũng sẽ biến thiên chậm lại tương ứng. Theo Zhu và cộng sự (2008), ảnh hưởng của $\mathrm{CH}$ đến chất lượng trái cây trong quá trình bảo quản liên quan tới nguồn gốc, đặc tính và nồng độ của $\mathrm{CH}$, kỹ thuật sử dụng $\mathrm{CH}$, loại trái cây và điều kiện bảo quản.

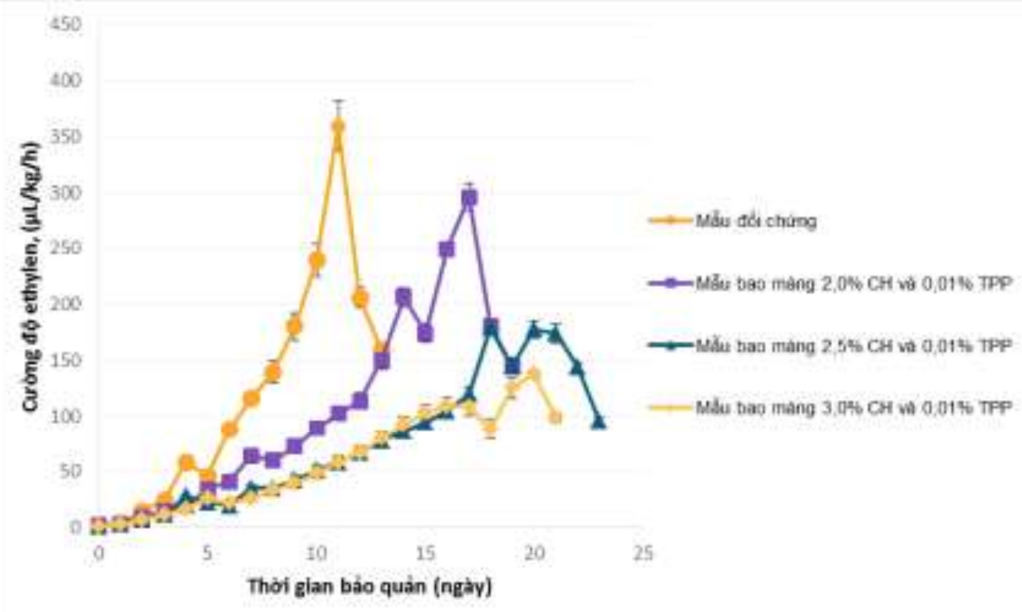

Hình 2. Tỷ lệ ethylen sản sinh của trái bơ trong quá tình bảo quản

\subsection{Sự hao hụt khối lượng trái bo trong quá trình bảo quản}

Kết quả bảo quản cho thấy, việc bao màng chitosan có ảnh hưởng có ý nghĩa thống kê $(p<0,05)$ đến sự thay đổi hao hụt khối lượng trái bơ trong quá trình bảo quản. Cụ thể, sau 11 ngày bảo quản, mẫu trái bơ không bao màng có phần trăm hao hụt khối lượng cao nhất (khoảng $25 \%$ ), so với gần $10 \%$ của mẫu được bao màng bởi dung dịch $2 \% \mathrm{CH}$ kết hợp $0,01 \% \mathrm{TPP}$, và khoảng $5 \%$ đối với mẫu được bao màng bởi 2,5 và $3 \% \mathrm{CH}$ kết hợp $0,01 \% \mathrm{TPP}($ Hình 3$)$.

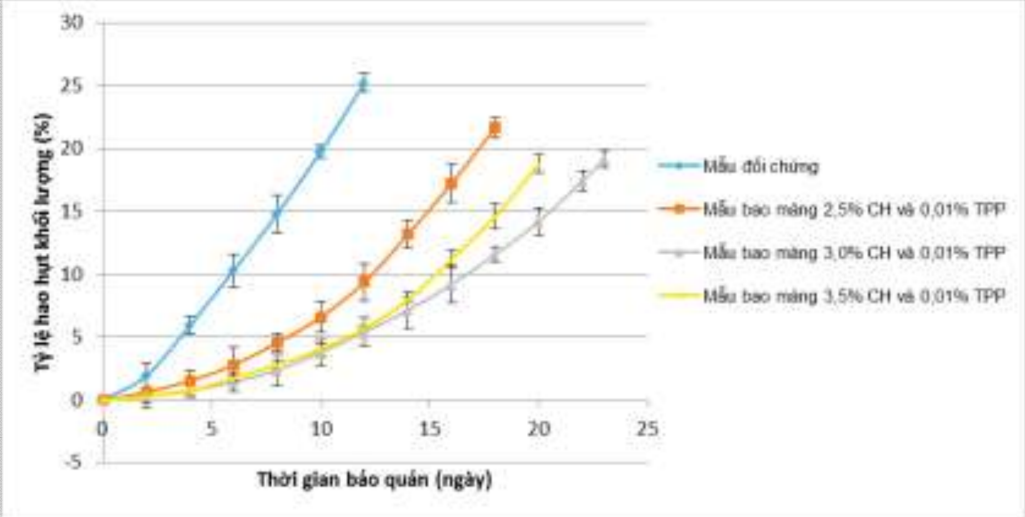

Hình 3. Tỷ lệ hao hụt khối lượng trái bơ trong thời gian bảo quản

Điều này có thể được giải thích bởi khả năng ngăn cản sự mất nước và tiêu hao chất khô do quá trình hô hấp trong khi bảo quản bởi màng $\mathrm{CH}$. Theo Hà Văn Thuyết và cộng sự (2000), trong quá trình bảo quản, sự giảm khối lượng chủ yếu do mất nước $(75-85 \%)$, tiếp đó là do tiêu hao chất khô trong quá trình hô hấp duy trì sự sống cho tế bào $(15-25 \%)$. Do khảo sát ở cùng điều kiện nhiệt độ và độ ẩm, nên nhân tố chính giúp hạn chế sự hao hụt khối lượng của bơ là do nồng độ chitosan. Kết quả cho thấy, nếu không bảo quản hoặc bảo quản với nồng độ chitosan thấp bơ vẫn có thể hô hấp tốt nên dẫn đến quá trình mất nước và tiêu hao hàm lượng chất khô nhanh chóng dẫn đến sư hao hụt khối lượng lớn trong quá trình bảo quản. Ngược lại, nếu bảo quản ở nồng độ $\mathrm{CH}$ quá cao, màng hình thành quá dày làm ức chế quá trình hô hấp của bơ có thể sẽ dẫn đến quá trình thối hỏng. Quá trình thối hỏng của trái sẽ làm tiêu hao một lượng lớn hàm lượng chất khô của trái, gây nên sự hao hụt khối lượng của trái. Kết quả này cũng phù hợp với nhận định của Ghaouth và cộng sự (2012) [17]. Hao hụt khối lượng trong quá trình bảo quản có sự khác nhau giữa các loại trái cây phụ thuộc vào đặc tính vốn có của chúng chẳng hạn như cấu trúc hay thành phần hóa học của lớp biểu bì và đồng thời còn phụ thuộc vào phương phương pháp bảo quản. Đối với bảo quản 
bơ bằng phương pháp nhúng tạo màng từ dung dịch chitosan, sự hao hụt khối lượng còn phụ thuộc vào nồng độ chitosan, nhiệt độ và độ ẩm của môi trường bảo quản. Kết quả này phù hợp với công bố của Tesfay và cộng sự (2017) màng chitosan, carboxymethyl cellulose và dịch chiết lá chùm ngây làm chậm quá trình hao hụt khối lượng của trái bơ so với mẫu đối chứng, không bao màng [13].

\subsection{Hàm lượng vitamin $C$}

Hàm lượng vitamin $\mathrm{C}$ của các mẫu được xác định ở thời điểm bắt đầu và thời điểm kết thúc thí nghiệm. Mẫu bơ được bao màng bởi dung dịch $\mathrm{CH} 2,5 \%$ kết hợp $0,01 \%$ TPP có độ hao hụt vitamin $\mathrm{C}$ khoảng $14 \%$ sau 20 ngày bảo quản, thấp hơn so các mẫu bơ được bao màng bởi dung dịch $\mathrm{CH} 2$ và 3,5\% kết hợp $0,01 \%$ TPP. Đồng thời, sự hao hụt của các mẫu trái bơ bao màng thấp hơn khi so sánh với mẫu bơ đối chứng sau 13 ngày bảo quản ở cùng điều kiện nhiệt độ và độ ẩm. Kết quả này tương đồng với sự thay đổi trong cường độ hô hấp, lượng ethylene sản sinh, thời gian bảo quản của các mẫu ở những điều kiện bảo quản khác nhau đã trình bày ở trên.

\section{KẾT LUẬn}

Kỹ thuật bao màng sử dụng chitosan có hỗ trợ của sodium tripopolyphosphate có tác dụng tích cực trong việc làm chậm quá trình chín của trái bơ khoảng 2 lần so với mẫu đối chứng ở nhiệt độ $10 \pm 2^{\circ} \mathrm{C}$. Nồng độ chitosan thay đồi tác động khác biệt tới quá trình hô hấp sau thu hoạch của trái bơ, nồng độ $2,5 \%$ được đánh giá là phù hợp hơn khi so sánh với các nồng độ khác.

\section{TÀI LIỆU THAM KHẢO}

1. Hurtado-Fernández, E., Fernández-Gutiérrez, A., and Carrasco-Pancorbo, A., Avocado fruit- Persea americana. 2018. 10.1016/b978-0-12-803138-4.00001-0: p. 37-48, DOI: 10.1016/b978-0-12-803138-4.00001-0

2. Dreher, M.L. and Davenport, A.J., Hass avocado composition and potential health effects. Crit Rev Food Sci Nutr, 2013. 53(7): p. 738-50, DOI: 10.1080/10408398.2011.556759

3. Yahia, E.M. and Woolf, A.B., Avocado ( Persea americana Mill.). 2011. 10.1533/9780857092762.125: p. 125-186e, DOI: 10.1533/9780857092762.125

4. Gwanpua, S.G., Qian, Z., and East, A.R., Modelling ethylene regulated changes in 'Hass' avocado quality. Postharvest Biology and Technology, 2018. 136: p. 12-22, DOI: 10.1016/j.postharvbio.2017.10.002

5. Arpaia, M.L., Collin, S., Sievert, J., and Obenland, D., 'Hass' avocado quality as influenced by temperature and ethylene prior to and during final ripening. Postharvest Biology and Technology, 2018. 140: p. 76-84, DOI: 10.1016/j.postharvbio.2018.02.015

6. Arpaia, M.L., Collin, S., Sievert, J., and Obenland, D., Influence of cold storage prior to and after ripening on quality factors and sensory attributes of 'Hass' avocados. Postharvest Biology and Technology, 2015. 110: p. 149157, DOI: 10.1016/j.postharvbio.2015.07.016

7. Cowan, A.K. and Wolstenholme, B.N., Avocado. 2016. 10.1016/b978-0-12-384947-2.00049-0: p. 294-300, DOI: $10.1016 / \mathrm{b} 978-0-12-384947-2.00049-0$

8. Wang, X., Kobiler, I., Lichter, A., Leikin-Frenkel, A., Pesis, E., and Prusky, D., 1-MCP prevents ethyleneinduced accumulation of antifungal diene in avocado fruit. Physiological and Molecular Plant Pathology, 2005. 67(3-5): p. 261-267, DOI: 10.1016/j.pmpp.2006.03.002

9. Toản, N.V., Chi, P.T.K., Hołơng, N.T.D., Thảo, Đ.T.T., and Tán, L.V., Nghiên cứu ảnh hưởng của 1Methycyclopropene đến quá trình sinh tổng hợp ethylene của quả bơ (Persea anericana) sau thu hoạch. Gazi University Journal of Science, 2016.

10. Jeong, J., Huber, D.J., and Sargent, S.A., Delay of avocado (Persea americana) fruit ripening by 1 methylcyclopropene and wax treatments. Postharvest Biology and Technology, 2003. 28(2): p. 247-257, DOI: 10.1016/s0925-5214(02)00176-x

11. Aguirre-Joya, J.A., Ventura-Sobrevilla, J., Martínez-Vazquez, G., Ruelas-Chacón, X., Rojas, R., RodríguezHerrera, R., and Aguilar, C.N., Effects of a natural bioactive coating on the quality and shelf life prolongation at 
different storage conditions of avocado (Persea americana Mill.) cv. Hass. Food Packaging and Shelf Life, 2017. 14: p. 102-107, DOI: 10.1016/j.fpsl.2017.09.003

12. Saucedo-Pompa, S., Rojas-Molina, R., Aguilera-Carbó, A.F., Saenz-Galindo, A., Garza, H.d.L., Jasso-Cantú, D., and Aguilar, C.N., Edible film based on candelilla wax to improve the shelf life and quality of avocado. Food Research International, 2009. 42(4): p. 511-515, DOI: 10.1016/j.foodres.2009.02.017

13. Tesfay, S.Z. and Magwaza, L.S., Evaluating the efficacy of moringa leaf extract, chitosan and carboxymethyl cellulose as edible coatings for enhancing quality and extending postharvest life of avocado (Persea americana Mill.) fruit. Food Packaging and Shelf Life, 2017. 11: p. 40-48, DOI: 10.1016/j.fps1.2016.12.001

14. Adkins, M.F., Hofman, P.J., Stubbings, B.A., and Macnish, A.J., Manipulating avocado fruit ripening with 1 methylcyclopropene. Postharvest Biology and Technology, 2005. 35(1): p. 33-42, DOI: 10.1016/j.postharvbio.2004.05.021

15. Ku, V.V.V., Wills, R.B.H., and Ben-Yehoshua, S., 1-Methylcyclopropene Can Differentially Affect the Postharvest Life of Strawberries Exposed to Ethylene. 1999. 34(1): p. 119, DOI: 10.21273/hortsci.34.1.119

16. Maftoonazad, N. and Ramaswamy, H.S., Postharvest shelf-life extension of avocados using methyl cellulosebased coating. LWT - Food Science and Technology, 2005. 38(6): p. 617-624, DOI: 10.1016/j.1wt.2004.08.007

17. Toản, N.V., Điều tiết quá trình sinh tổng hợp ethylene nhằm kéo dài thời gian chín sau thu hoạch của quả chuối tiêu, in Food Technology. 2012, Da Nang University

18. $\mathrm{Li}, \mathrm{H}$. and $\mathrm{Yu}, \mathrm{T}$., Effect of chitosan on incidence of brown rot, quality and physiological attributes of postharvest peach fruit. Journal of the Science of Food and Agriculture, 2001. 81: p. 269-274, DOI: 10.1002/10970010(20010115)81:2<269::AID-JSFA806>3.0.CO;2-F

19. Salvador, L., Miranda, S., Aragon, N., and Lara Sagahon, A.V., Chitosan coating on avocado fruit. The Revista de la Sociedad Quimica de Mexico, 1999. 43: p. 18-23.

20. Bangun, H., Tandiono, S., and Arianto, A., Preparation and evaluation of chitosan-tripolyphosphate nanoparticles suspension as an antibacterial agent. Journal of Applied Pharmaceutical Science, 2018. 8(12): p. 147156, DOI: $10.7324 /$ japs.2018.81217

21. Suntornsuk, L., Gritsanapun, W., Nilkamhank, S., and Paochom, A., Quantitation of vitamin C content in herbal juice using direct titration. Journal of Pharmaceutical and Biomedical Analysis, 2002. 28(5): p. 849-855, DOI: https://doi.org/10.1016/S0731-7085(01)00661-6

22. Zhu, Effects of chitosan coating on postharvest quality of mango (mangifera indica l. cv. tainong) fruits. 2008.

23. Bai, R.-K., Huang, M.-Y., and Jiang, Y.-Y., Selective permeabilities of chitosan-acetic acid complex membrane and chitosan-polymer complex membranes for oxygen and carbon dioxide. Polymer Bulletin, 1988. 20(1): p. 83-88, DOI: 10.1007/BF00262253

Ngày nhận bài: 27/11/2019

Ngày chấp nhận đăng: 25/03/2020 